\title{
Effects of the Invasive Little Fire Ant (Wasmannia auropunctata) on Ant Community Composition on UF Campus
}

\author{
Alexandra Nielsen, Rachel Atchison, and Andrea Lucky \\ University of Florida
}

Faculty Mentor: Andrea Lucky, Department of Entomology and Nematology

\begin{abstract}
Invasive species are a serious threat to Florida's native ecosystems and can have significant economic impacts. The invasive little fire ant (Wasmannia auropunctata) was first observed on the University of Florida's (UF) campus in the Field and Fork Gardens in Summer 2018 and a targeted eradication of this population began in Fall 2018. This project aimed to compare ant community composition in invaded and uninvaded areas to better understand how ant invasions affect native ant communities. For comparison with Field and Fork Gardens invaded sites, four additional sites on UF's campus were surveyed for ants through leaf litter sampling. Samples were sorted and all ants identified to the genus level; samples from invaded sites were identified to species. In samples from invaded sites, the community had lower species richness and a lower relative abundance of ant species compared to uninvaded communities. Determining how the invasion of the little fire ant affects ant communities is important as invasive ants do not fill the same ecosystem roles as native ants, such as seed dispersal and mutualist interactions. Data on community composition in uninvaded areas could be useful to land managers and researchers in efforts to restore a site after eradication has been achieved.
\end{abstract}

Keywords: invasive ants, species richness, community composition

\section{Introduction}

The little fire ant (Wasmannia auropunctata (Roger)) is a small invasive ant (workers are 1 to $2 \mathrm{~mm}$ in length) native to Central and South America (Holway et al., 2002; Wetterer \& Porter, 2003). This ant has been designated as one of the world's worse invasive alien species by the International Union for the Conservation of Nature (Lowe et al., 2000). Impacts of little fire ant (LFA) invasions include displaced native ant populations, reduced invertebrate populations, and negative impacts on native vertebrates and agriculture (Clark et al., 1982; Le Breton et al., 2003; Wetterer et al., 1999; Wetterer \& Porter, 2003). Plants that rely on ants to disperse seeds could suffer from LFA replacing native ants that participate in this form of mutualism between the plant and ant, as ant body size is linked to seed dispersal distance, with larger ants carrying seeds 
farther (Ness et al., 2004); LFA are smaller than many ants native to the area, with the exception of Solenopsis molesta (Say) (MacGown, 2014).

The discovery of LFA in Gainesville, Florida is the first time this species has been recorded in Alachua County, and the farthest north it has been recorded as an established population in Florida, according to Global Ant Biodiversity Informatics data (Guénardet al., 2017; Janicki et al., 2016). Since invasive ants do not fill the same roles as native ants, this study aimed to investigate the impacts of LFA invasions on local ant community composition by asking the following specific questions: Does LFA presence affect mean species richness? Do other factors such as location and habitat type affect mean species richness? The results of this study will provide knowledge on the mean species richness and species present in invaded and uninvaded locations on campus, as well as more information on the extent of the LFA invasion.

\section{Methods}

\section{Study Area}

This study was carried out on University of Florida's main campus in Gainesville, Florida. Five locations were sampled around campus: Harmonic Woods, Ficke Gardens, University Gardens, Field and Fork Gardens, and the west portion of the Natural Area Teaching Lab (referred to as NATL West) (Figure 1). Each sampled location was partitioned into habitat types: wooded, open, and cultivated. Wooded and open habitats were present in all locations, while cultivated habitats were only present in Field and Fork and NATL West. Two rounds of sampling occurred, with the first occurring on June 21st and 24th, 2019 and the second on September 19th and 26th, 2019. One transect (13.7 meters long) was collected for each habitat type in each location per sampling.

\section{Leaf Litter Sampling}

Winkler leaf litter sampling was conducted along transect lines in each habitat type for all locations; this method involves sifting collected leaf litter through a bag containing a coarse mesh screen. The resulting siftate is placed in mesh bags suspended in enclosed Winkler bags. Arthropods fall from the mesh bags into a cup of ethanol located at the base of each Winkler bag. Each round of sampling resulted in two samples per location, except for Field and Fork and NATL West, which both contain three habitat types, thus three samples were collected from each location. One transect was established in each area, with a transect length of 13.7 meters (45 feet). The transects established for the two rounds of sampling started and ended in 
approximately the same locations. Each sample of leaf litter was collected from a 0.84 square meter (nine square feet) area along the transect line, starting at the beginning of the line and sampling every 4.6 meters (15 feet) until the end of the 13.7 meter line was reached. This resulted in four samples from each transect line. Over two rounds of sampling, 96 total samples were collected. Once samples were collected, they were hung in a greenhouse for 72 hours, transferred into vials, and stored in a freezer until they were sorted.

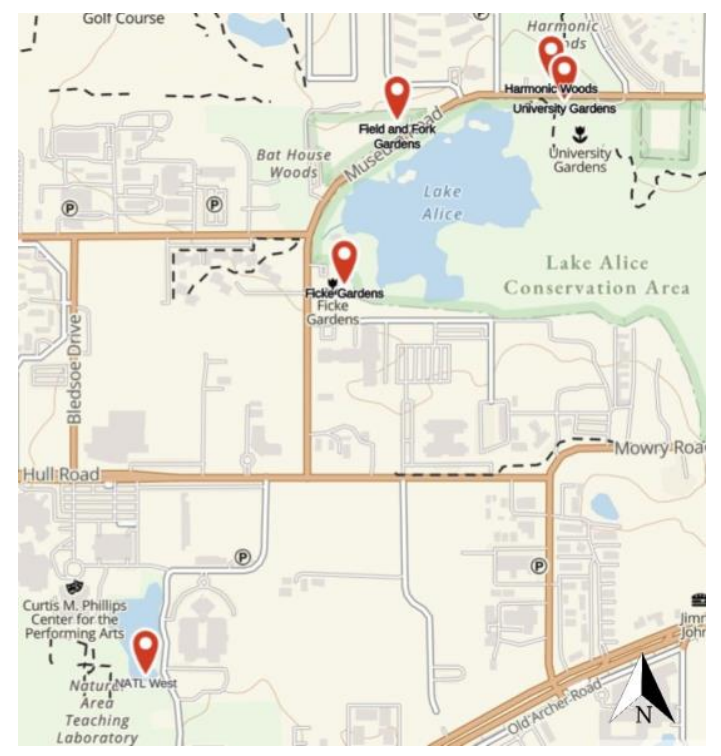

Figure 1. Red markers show each sampling location on a map of the University of Florida campus (Gaia GPS \& OpenStreetMap)

\section{Sample Processing and Data Analysis}

Samples were sorted by separating any ants from the leaf litter, then identifying each individual to the genus level using morphological keys (MacGown, 2014). Ants from samples containing LFA were identified to the species level (MacGown, 2014). A total of 94 samples were sorted, as two samples were dropped while being transferred to vials. Of these 94 samples, 23 contained LFA and were identified to the morphospecies. JMP (version 15.0) was used to produce graphs and analyze the data. An ANOVA was run with mean species richness as the response variable; the predictor variables were location, habitat type, and LFA presence. 
Table 1. Species of individuals found in samples in which W. auropunctata was present, organized by origin (Guénardet al., 2017; Janicki et al., 2016).

\begin{tabular}{lll}
\hline Native Species & Exotic Species & Unknown Origin \\
\hline Hypoponera opacior (Forel) & Brachymyrmex patagonicus (Mayr) & Strumigenys boneti (Brown) \\
\hline Pheidole dentata (Mayr) & Cardiocondyla obscurior (Wheeler) & \\
\hline Pheidole dentigula (Smith) & Cyphomyrmex rimosus (Spinola) & \\
\hline Pheidole metallescens (Emery) & Strumigenys eggersi (Emery) & \\
\hline Solenopsis molesta (Say) & & \\
\hline
\end{tabular}

\section{Results}

A total of 19 morphospecies from 15 genera were recorded. The most species rich genus was Pheidole (three species), followed by Strumigenys and Solenopsis with two species each. Overall, in samples where LFA was present, there were five native species, four exotic species (not including LFA), and one species of unknown origin (Table 1). The location with the highest mean richness was Harmonic Woods; the lowest mean richness was found at NATL West (Figure 2). Wooded habitats were the most species rich habitat type, followed by open habitats, then cultivated habitats with the lowest species richness (Figure 3). Field and Fork Gardens had the highest proportion of samples with LFA present, while University Gardens had none present (Figure 4). There was no statistically significant correlation between lower mean species richness and LFA presence (Figure 5).

\section{Discussion}

LFA presence does not appear to affect mean species richness; differences in mean species richness can be attributed to habitat type and sampling location. An example of this is NATL West, the site most analogous to the Field and Fork Gardens in terms of habitat type and mean species richness. Out of 23 samples from this site, one sample contained a single LFA worker; in comparison, 20 of the 23 Field and Fork samples contained workers, with some samples containing over 1,000 workers. Based on the similar habitat types and low mean species richness, NATL West is a site that could potentially be invaded successfully by LFA. 


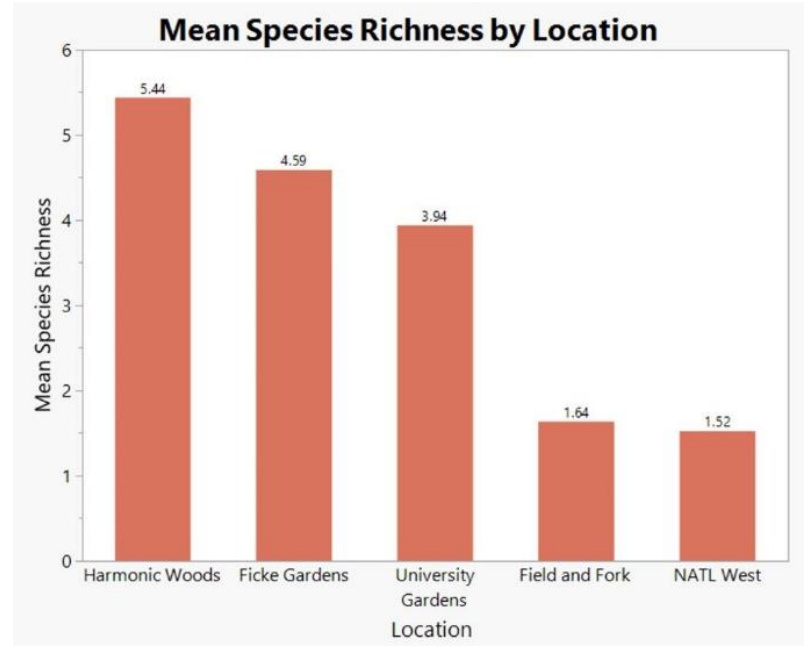

Figure 2. Mean species richness for each location sampled

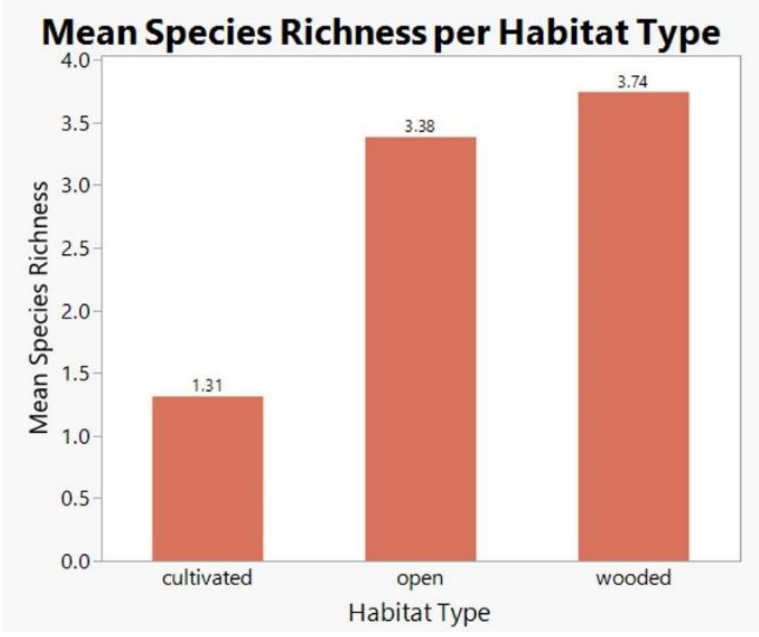

Figure 3. Mean species richness for each type of habitat sampled 


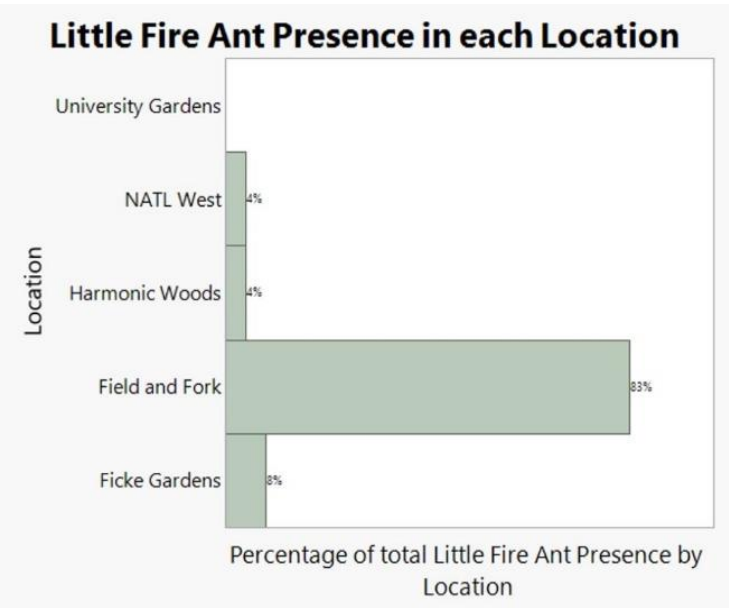

Figure 4. Proportion of samples from each location in which W. auropunctata was present

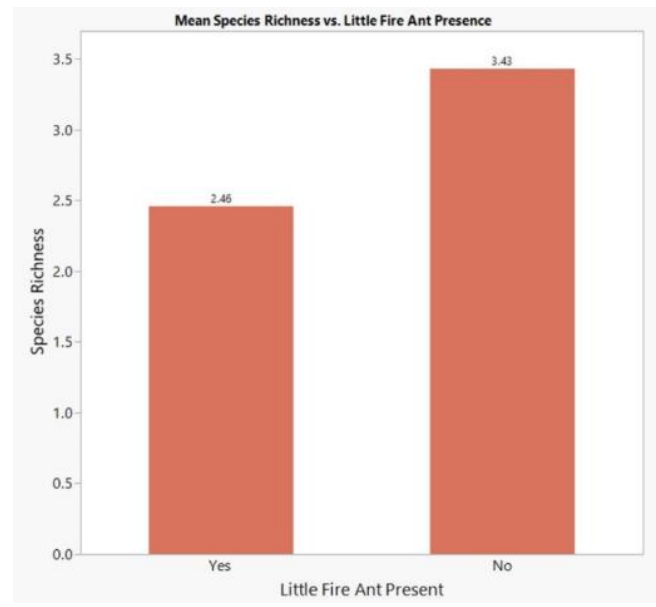

Figure 5. Mean species richness in samples where W. auropunctata was present or absent Species composition data was collected for samples containing LFA, showing that native species are still present in invaded areas, along with other invasive ant species. Locations not previously known to be invaded by LFA were discovered, such as NATL West, Harmonic Woods, and Ficke Gardens; these areas had much lower proportions of samples containing LFA compared to Field and Fork Gardens (Figure 4). There were low numbers of individuals of other species present in samples containing LFA, as other species have a difficult time competing with dense populations of this invasive ant (Clark et al., 1982). It has been suggested that Pheidole species play a role in limiting LFA population sizes in both native and invaded ranges, such as Cameroon (Le Breton et al., 2003; Mbenoun Masse et al., 2019). Alternatively, the presence of LFA in a New Caledonian rainforest led to the extinctions of Pheidole species along with all other native species in the sampled area (Le Breton et al., 2003). Three native Pheidole species 
were present in samples where LFA was present; continued sampling of invaded areas could show the results of interactions between LFA and Pheidole in this location.

Continuing to sample these areas over time to monitor LFA population size and community composition will be important in helping on-campus natural areas and agricultural operations decide future steps towards eradication. Continued sampling will also provide researchers with information on how ant communities on campus respond to the invasion over time.

Further research on this topic should be carried out in order to compare uninvaded communities with invaded communities and to establish if invasion follows reduced community diversity or vice versa.

\section{Acknowledgements}

This work was funded by the UF Center for Undergraduate Research through the University Scholars Program. I would like to thank everyone in the Lucky Lab, Rachel Atchison for guidance in the design and completion of this study, and Dr. Andrea Lucky for support and mentorship throughout the project.

\section{References}

Clark, D. B., Guayasamin, C., Pazmino, O., Donoso, C., \& de Villacis, Y. P. (1982). The tramp ant Wasmannia auropunctata: Autecology and effects on ant diversity and distribution on Santa Cruz Island, Galapagos. Biotropica, 14(3), 196. https://doi.org/10.2307/2388026

Gaia GPS \& OpenStreetMap (Cartographer). (2020). University of Florida campus [Topo map].

Guénard, B., Weiser, M., Gomez, K., Narula, N., Economo, E.P. (2017) The global ant biodiversity informatics (GABI) database: A synthesis of ant species geographic distributions. Myrmecological News 24: 83-89.

Holway, D. A., Lach, L., Suarez, A. V, Tsutsui, N. D., \& Case, T. J. (2002). The causes and consequences of ant invasions. Annu. Rev. Ecol. Syst, 33, 181-233. https://doi.org/10.1146/annurev.ecolsys.33.010802.150444

Janicki, J., Narula, N., Ziegler, M., Guénard, B. Economo, E.P. (2016) Visualizing and interacting with large-volume biodiversity data using client-server web-mapping applications: The design and implementation of antmaps.org. Ecological Informatics 32: 185-193

Le Breton, J., Chazeau, J., \& Jourdan, H. (2003). Immediate impacts of invasion by Wasmannia auropunctata (Hymenoptera: Formicidae) on native litter ant fauna in a New Caledonian rainforest. Austral Ecology, 28(2), 204-209. https://doi.org/10.1046/j.1442-9993.2003.01266.x

Lowe S., Brown M.,Boudejelas., D. P. (2000). 100 of the world's worst invasive alien species: A selection from the global invasive species database. Invasive Species Specialist Group. www.issg.org/booklet.pdf 
MacGown, J. A. (2014). Mississippi Entomological Museum, Ants (Formicidae) of the Southeastern United States - Keys to subfamilies, genera, and species in or possible in the southeastern United States. Retrieved March 24, 2020, from https://mississippientomologicalmuseum.org.msstate.edu/Researchtaxapages/Formicidaepages/Id entification.Keys.htm

Mbenoun Masse, P. S., Tindo, M., Djieto-Lordon, C., Mony, R., \& Kenne, M. (2019). Diversity of ant assemblages (Hymenoptera: Formicidae) in an urban environment in Cameroon during and after colonization of the area by Wasmannia auropunctata. European Journal of Entomology, 116, 461-467. https://doi.org/10.14411/eje.2019.047

Ness, J. H., Bronstein, J. L., Andersen, A. N., \& Holland, J. N. (2004). Ant body size predicts dispersal distance of ant-adapted seeds: Implications of small-ant invasions. Ecology, 85(5).

Wetterer, J K, Walsh, P. D., \& White, L. J. T. (1999). Wasmannia auropunctata (Roger) (Hymenoptera: Formicidae), a destructive tramp-ant, in wildlife refuges of Gabon.

Wetterer, James K, \& Porter, S. D. (2003). The little fire ant, Wasmannia auropunctata: Distribution, impact and control. 